\title{
The Effect_of Azathioprine on
}

\section{Gammaglobulin Synthesis in Man}

\author{
Joshua Levy, Eugene V. Barnett, Norman S. MacDonald, \\ James R. Kinengerg, and Carl M. Pearson \\ From the Departments of Medicine and Radiology, University of California at \\ Los Angeles School of Medicine, University of California, Los Angeles, \\ California 90024, and the Research and Medical Services, Veterans \\ Administration Hospital (Wadsworth) Los Angeles, California 90073
}

\begin{abstract}
A B S T RACT The effect of azathioprine therapy on gammaglobulin synthesis was evaluated in nine patients with rheumatic disorders. The rates of synthesis of IgG and IgM were calculated before and after 4 months of azathioprine treatment using turnover studies of radioiodinated gammaglobulins.

The synthesis of IgG decreased $33.4 \%$ of the initial IgG synthetic rate. Seven of nine patients showed reductions of IgG synthesis ranging from 16.8 to $74.1 \%$. IgM production decreased from 24.5 to $74.2 \%$ in eight of nine patients with a mean reduction of $40.9 \%$. Studies before and after a control period of 4 months of placebo in six patients revealed a mean increase in IgG and IgM synthesis. Serum immunoglobulin concentrations after 4 months of azathioprine treatment were not consistently reduced and did not parallel changes in immunoglobulin synthesis.

Reduced gammaglobulin synthesis may play a role in the therapeutic action of this and other "immunosuppressive" drugs.
\end{abstract}

\section{INTRODUCTION}

The purine analogue 6-mercaptopurine (6MP) ${ }^{2}$ and its congener azathioprine have found increasing use in a wide variety of autoimmune diseases. Despite their common usage, the mechanism of their therapeutic action remains unknown. These drugs are known to inhibit purine biosynthesis and to give rise to abnormal purine bases in both DNA, RNA, and a number of coenzymes (1). Immunosuppressive actions reported for purine

Received for publication 14 September 1971 and in revised form 25 February 1972.

${ }^{1}$ Abbreviations used in this paper: 6MP, 6-mercaptopurine; PPD, purified protein derivative. antagonists which may play a role in the treatment of immunologically mediated diseases have included alterations of cellular immunity (2) and inhibition of antibody synthesis (3).

Suppression of primary and secondary humoral antibody responses by purine analogues in both animal and man has been well documented (4-7). Wolff and Goodman (8) in addition, have shown 6MP and 6-thioguanine to depress immunoglobulin levels in normal rabbits, and Herrod, Myers, Self, and Cooper (9) have demonstrated hypogammaglobulinemia in rabbits when treated from birth with 6-methylmercaptopurine. Mott, Wochner, and Wolff (10), using turnover studies, showed the hypogammaglobulinemia secondary to $6 \mathrm{MP}$ administration in rabbits to be a result of decreased gammaglobulin synthesis and not increased catabolism. These effects on rabbit gammaglobulin synthesis, however, may not be applicable to therapy in man as the dose of 6MP administered $(18 \mathrm{mg} / \mathrm{kg}$ per day) greatly exceeded human therapeutic dosage levels and resulted in the death of 8 of 20 rabbits before the completion of a 10 day course of treatment.

Studies in humans treated with azathioprine have revealed no consistent reduction in serum IgG or IgM levels $(7,11,12)$. Serum immunoglobulin concentration, however, may be an unreliable guide to gammaglobulin synthesis since a decrease in synthesis may be accompanied by a decrease in catabolism and serum concentration may remain unchanged. Metabolic studies with radioiodinated gammaglobulins make possible the calculation of the synthetic and catabolic rates of these proteins (13). Using such turnover studies we have determined the effects of azathioprine therapy on gammaglobulin synthesis in patients with severe and progressive rheumatic diseases. 


\section{METHODS}

Subjects. The synthetic rates of $\mathrm{IgG}$ and $\mathrm{IgM}$ were studied serially before starting azathioprine $3 \mathrm{mg} / \mathrm{kg}$ per day and again after 4 months of treatment in five patients with rheumatoid arthritis, two with systemic lupus erythematosus, and two with psoriatic arthritis. In six of the nine patients synthetic rates were also determined before and after a control period of 4 months on placebo. All patients with rheumatoid arthritis demonstrated positive tests for rheumatoid factor and had either classical or definite rheumatoid arthritis according to criteria of the American Rheumatism Association (14). The two patients with systemic lupus erythematosus were judged to have active disease, including renal involvement, by clinical, serologic, and histologic criteria. Both patients demonstrated serum antinuclear antibodies at time of study. Treatment with salicylates, indomethacin, and corticosteroids were maintained constant during the study period.

Preparation of IgM and IgG fractions for turnover studies. IgM was separated from the serum of a patient with Waldenstrom's macroglobulinemia by ammonium sulfate precipitation followed by DEAE-cellulose chromatography and gel filtration on Sephadex G-200 and Sepharose 4B (Pharmacia Fine Chemicals Inc., Piscataway, N. J.). The IgM fraction was determined to be homogenous and to lack any 7S components by ultracentrifugal analysis. In addition, immunochemical techniques of Ouchterlony gel diffusion and immunoelectrophoresis revealed single precipitin lines with no contaminating proteins. The IgM preparation was found to lack any antiglobulin activity by latex fixation (15) and sensitized sheep cell (16) tests.

Purified IgG was obtained from Merck Sharp \& Dohme (West Point, Pa.) as Gamma Gee, lot No. 0973J. The preparation was found, by radial immunodiffusion (17), to contain greater than 99\% IgG and with DEAE-cellulose column chromatography, greater than $97 \%$ of the protein fraction was eluted in a single homogenous peak with $0.01 \mathrm{M}$ phosphate buffer of $\mathrm{pH}$ 8.0. The preparation was found to lack antinuclear antibody activity as determined by an immunofluorescent technique using human leukocytes as a substrate (18). Both normal volunteers and patients were studied with a single lot of IgG and with portions of a single preparation of IgM.

The IgG and IgM preparations were labeled with ${ }^{181} \mathrm{I}$ and ${ }^{125} \mathrm{I}$, respectively, by the iodine monochloride method of McFarlane (19) as previously described (20). Iodinated preparations were studied in normal volunteers at the time of study in patients with rheumatic diseases.

Study protocol. Patients received 5 drops of Lugol's solution twice daily for 3 days before and during the entire study period to prevent thyroidal uptake of released radioiodine. Approximately $10 \mu \mathrm{Ci}$ of each labeled immunoglobulin was injected intravenously and the biological halflife was calculated over a 21 day period by serial determinations of radioactivity in the blood and urine in a gamma well counter, Nuclear-Chicago Corporation, Des Plaines, Ill., model No. 42-33 and by serial counts of total body radioactivity for ${ }^{101} \mathrm{I}$ in a total body counting chamber.

Plasma volumes were calculated by evaluation of $10-\mathrm{min}$ IgM- ${ }^{125}$ I samples. Patients with proteinuria were studied with urinary quantitative immunoglobulin determinations and had urine analyzed for protein-bound radioactivity. In no patient was significant urinary protein-bound radioactivity found.

Serial immunoglobulin concentrations were determined using the radial immunodiffusion assay (17) to establish the steady state in all our patients. Rheumatoid factor was evaluated and titers quantitated by tube dilution techniques using both latex particles coated with human gammaglobulin (15) and sensitized sheep cells coated with rabbit gammaglobulin (16). All patients were studied for anti-

TABLE I

IgG and IgM Metabolism before and after 4 Months of Azathioprine Therapy

\begin{tabular}{|c|c|c|c|c|c|c|c|c|c|c|c|c|c|c|c|c|}
\hline \multirow{2}{*}{$\begin{array}{l}\text { Patient } \\
\text { and } \\
\text { diag- } \\
\text { nosis }\end{array}$} & \multicolumn{2}{|c|}{$\begin{array}{l}\text { IgG serum } \\
\text { concentration }\end{array}$} & \multicolumn{2}{|c|}{$\begin{array}{c}\text { IgG survival } \\
\left(t \frac{1}{3}\right)\end{array}$} & \multicolumn{2}{|c|}{$\begin{array}{l}\text { Per cent of } \\
\text { total body IgG } \\
\text { catabolized } \\
\text { per day }\end{array}$} & \multicolumn{2}{|c|}{$\begin{array}{l}\text { IgG absolute } \\
\text { synthetic rate }\end{array}$} & \multicolumn{2}{|c|}{$\begin{array}{l}\text { IgM serum } \\
\text { concentra- } \\
\text { tion }\end{array}$} & \multicolumn{2}{|c|}{$\begin{array}{c}\text { IgM survival } \\
\left(t \frac{1}{2}\right)\end{array}$} & \multicolumn{2}{|c|}{$\begin{array}{l}\text { Per cent of } \\
\text { total body IgM } \\
\text { catabolized } \\
\text { per day }\end{array}$} & \multicolumn{2}{|c|}{$\begin{array}{l}\text { IgM absolute } \\
\text { synthetic rate }\end{array}$} \\
\hline & Before & After & Before & After & Before & After & Before & After & Before & After & Before & After & Before & After & Before & After \\
\hline & \multicolumn{2}{|c|}{$m g / 100 \mathrm{ml}$} & \multicolumn{2}{|c|}{ days } & \multicolumn{2}{|l|}{$\%$} & \multicolumn{2}{|c|}{$m g / k g$ per day } & \multicolumn{2}{|c|}{$\mathrm{mg} / 100 \mathrm{ml}$} & \multicolumn{2}{|c|}{ days } & \multicolumn{2}{|l|}{$\%$} & \multicolumn{2}{|c|}{$m g / k g$ per day } \\
\hline \multicolumn{17}{|c|}{ Normal controls* } \\
\hline$\pm \mathrm{SE}$ & \multicolumn{2}{|c|}{$1070 \pm 180$} & \multicolumn{2}{|l|}{$18.0 \pm 1.4$} & \multicolumn{2}{|l|}{$3.9 \pm 0.4$} & \multicolumn{2}{|l|}{$34.5 \pm 5.7$} & \multicolumn{2}{|l|}{$95 \pm 5$} & \multicolumn{2}{|l|}{$9.3 \pm 0.9$} & \multicolumn{2}{|l|}{$8.1 \pm 1.0$} & \multicolumn{2}{|l|}{$6.0 \pm 1.3$} \\
\hline \multicolumn{17}{|c|}{ Rheumatoid arthritis } \\
\hline W. M. & 1370 & 1000 & 10.6 & 12.6 & 6.5 & 5.5 & 79.1 & 43.1 & 500 & 360 & 4.7 & 4.8 & 14.7 & 14.4 & 45.9 & 24.4 \\
\hline Y. M. & 4000 & 2400 & 10.8 & 13.2 & 6.4 & 5.3 & 238.0 & 118.1 & 170 & 160 & 3.5 & 12.8 & 19.8 & 5.4 & 21.7 & 5.6 \\
\hline F. M. & 1850 & 800 & 7.8 & 10.1 & 8.9 & 6.9 & 221.7 & 57.4 & 135 & 92 & 7.0 & 7.2 & 9.9 & 9.6 & 12.5 & 6.4 \\
\hline D. L. & 1950 & 1900 & 12.5 & 9.6 & 5.5 & 7.2 & 77.8 & 79.7 & 125 & 72 & 7.5 & 7.2 & 9.2 & 9.6 & 5.9 & 3.1 \\
\hline R. T. & 930 & 1150 & 13.2 & 15.1 & 5.2 & 4.6 & 50.5 & 50.5 & 58 & 70 & 5.5 & 8.0 & 12.6 & 8.7 & 4.9 & 3.7 \\
\hline \multicolumn{17}{|c|}{ Systemic lupus erythematosus } \\
\hline S. M. & 370 & 880 & 2.7 & 12.3 & 25.6 & 5.6 & 78.3 & 39.5 & 102 & 70 & 4.5 & 8.0 & 15.4 & 8.7 & 8.3 & 3.1 \\
\hline L. S. & 880 & 750 & 9.1 & 8.8 & 7.6 & 7.8 & 32.1 & 26.7 & 64 & 55 & 12.1 & 12.3 & 5.7 & 5.6 & 1.8 & 1.1 \\
\hline \multicolumn{17}{|c|}{ Psoriatic arthritis } \\
\hline G. H. & 900 & 800 & 15.3 & 25.0 & 4.5 & 2.8 & 33.1 & 18.3 & 45 & 40 & 12.3 & 11.0 & 5.6 & 6.3 & 1.2 & 1.2 \\
\hline M. S. & 1650 & 1650 & 13.5 & 17.0 & 5.1 & 4.1 & 56.7 & 44.3 & 79 & 85 & 8.6 & 12.2 & 8.1 & 5.7 & 2.8 & 2.1 \\
\hline
\end{tabular}

* Seven normal controls previously reported from this laboratory (ref. 20). 
nuclear antibodies by the indirect method of immunofluorescent staining of human leukocytes (18).

Delayed hypersensitivity was evaluated before and after drug and placebo periods using a panel of skin test antigens which included PPD, trichophyton, mumps, and monilia.

Analysis of data. IgG and IgM half-life, fractional catabolic rate, and absolute synthetic rate were calculated as previously described (20) from plasma radioiodine disappearance, total body radio-iodine disappearance, serum immunoglobulin concentration, plasma volume, and body weight by the method of Berson, Yalow, Schreiber, and Post (21), and the method of Sterling (22). Fractional catabolic rate was defined as the fraction of total body IgG or IgM catabolized per day and was derived from the equation for exponential decay. Fractional catabolic rate $(\%)=$ $\mathrm{Ln} 2 / \mathrm{t} \frac{1}{2}$ (half-life $)=0.693 / \mathrm{t} \frac{1}{2}$. Absolute synthetic rate was defined as the daily quantity of IgG or $\operatorname{IgM}$ catabolized, expressed as milligrams per kilogram per day. In the steady state, this rate also described the daily quantity of IgG or IgM synthesized.

\section{RESULTS}

The results of metabolic studies before and after 4 months of azathioprine therapy as summarized in Table $I$, reveal significant reductions in both $\operatorname{IgG}$ and $\operatorname{IgM}$ synthesis. After 4 months of therapy, IgG synthesis was reduced $33.4 \%$. Decreased IgG synthesis ranging from 16.8 to $74.1 \%$ was observed in seven of nine patients. During the 4 month control period, IgG synthesis showed a mean increase of $11 \%$. The difference between drug and control periods was found to be significant $(P<$ 0.01 ) by $t$ test analysis.

During azathioprine therapy, IgM synthesis decreased $40.9 \%$. Reductions ranging from 24.5 to $74.2 \%$ of initial IgM synthesis were observed in eight of nine patients. On placebo, IgM synthesis showed a mean increase of $35.8 \%$. Significance by $t$ test analysis corresponded again to a value of $P<0.01$. As these studies were made in conjunction with a double-blind crossover evaluation of azathioprine and placebo, four of the six patients, by chance, had placebo control periods after their trial of azathioprine. A tendency in some patients to return to

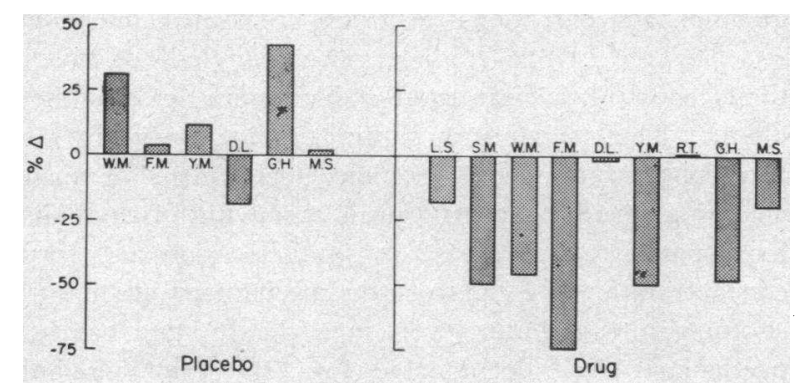

FIgURE 1 Per cent change of IgG synthesis from initial synthetic rate after 4 months of azathioprine therapy and in six of the same nine patients after 4 months of placebo. Patients W. M., Y. M., G. H., and M. S. were studied after 4 months of placebo after 4 months of azathioprine.

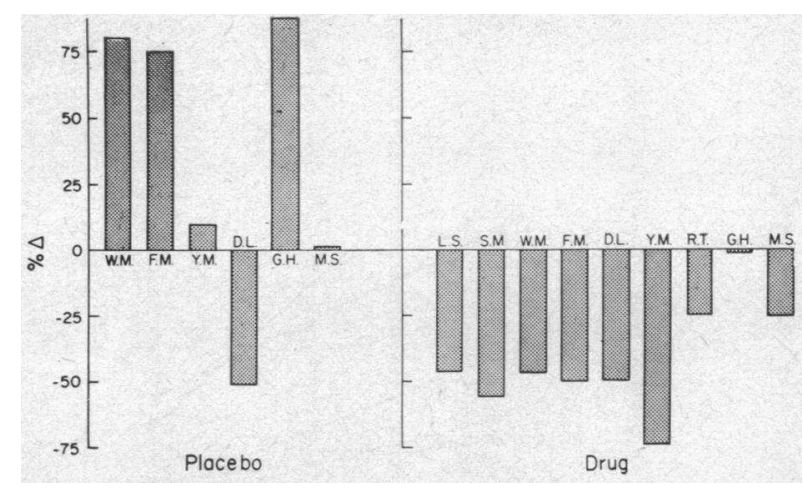

Figure 2 Per cent change of IgM synthesis from initial synthetic rate after 4 months of azathioprine therapy and in six of the same nine patients after 4 months of placebo.

synthetic levels previously suppressed by drug may explain the increased synthesis of both IgG and IgM on placebo revealed in Figs. 1 and 2.

Three of the four patients treated first with azathioprine and then with placebo demonstrated a pattern similar to that shown in Fig. 3 for patient W.M. This patient, in addition, showed a marked parallel between depression of gammaglobulin synthesis and lowering of rheumatoid factor titer. Increase in gammaglobulin synthesis during the subsequent placebo period was associated with a rise in rheumatoid factor titer. Of five patients with rheumatoid arthritis, three demonstrated a significant reduction in rheumatoid factor titer of at least 2 tube dilutions in latex fixation or sensitized sheep cell assays. Antinuclear antibodies in the two patients with systemic lupus erythematosus showed no change on therapy.

Immunoglobulin pool size and distribution were not altered by drug therapy as plasma volumes and the per

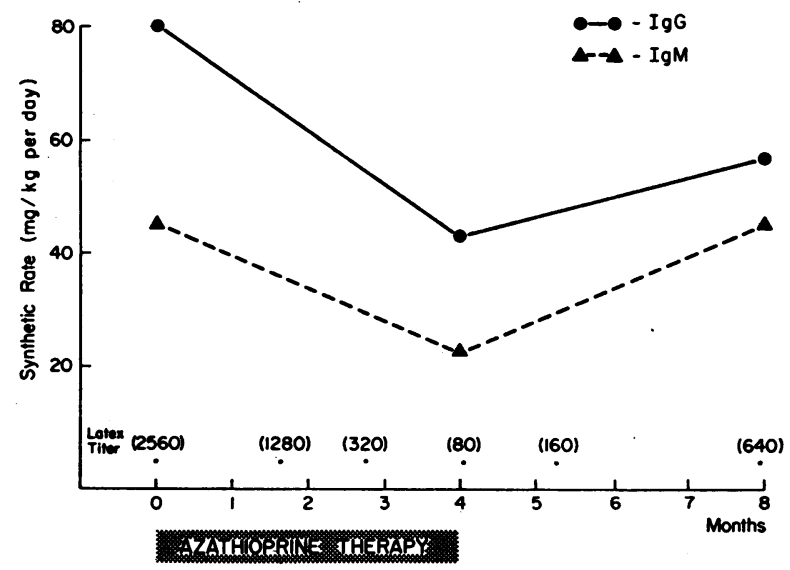

FIgure 3 Serial studies in patient W. M. of IgG and IgM synthetic rates and latex fixation titers on azathioprine and placebo. 


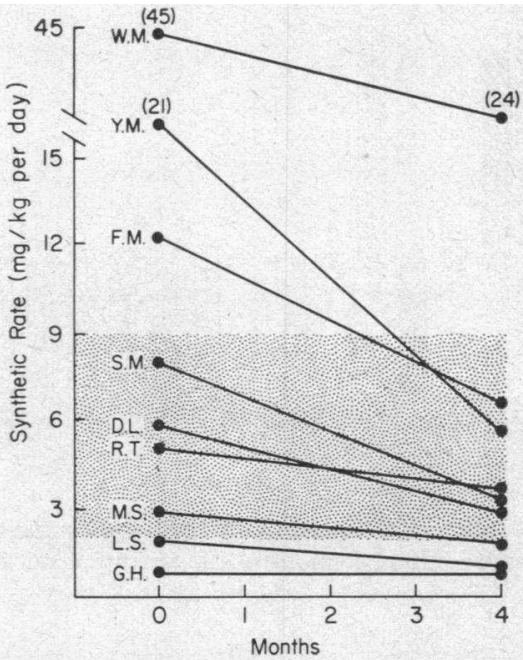

FIgURE 4 Effect of azathioprine on IgM absolute synthetic rate. The shaded area denotes the normal range of IgM absolute synthetic rates.

cent of the immunoglobulin pool intravascular did not change significantly. Decreased immunoglobulin synthesis was observed in patients with both normal as well as abnormally high initial gammaglobulin synthetic rates. Fig. 4 shows the effect of azathioprine therapy on absolute $\operatorname{IgM}$ synthetic rates and reveals that the higher the initial IgM synthetic rate the more significant is the reduction with azathioprine therapy.

Serum immunoglobulin concentration proved an unreliable indicator of decrease in immunoglobulin synthesis. Of seven patients showing a significant reduction in IgG synthesis, only three showed a decrease in serum IgG concentration. Similarly of eight patients with a significant reduction of IgM synthesis, five maintained essentially unchanged serum IgM concentrations. Leukopenia was not a prerequisite for suppression of gammaglobulin synthesis.

Delayed hypersensitivity remained essentially unchanged after both control and drug periods. Azathioprine therapy appeared not to affect any change in the skin test responses to antigens of a well established prior sensitization.

Objective clinical improvement in all three diseases in general paralleled decreases in gammaglobulin synthesis. Clinical benefit in patients with rheumatoid arthritis appeared to correlate best with reduction of IgM synthesis. A detailed analysis of our clinical studies of azathioprine and their correlation with experimental results will be the subject of a future report.

\section{DISCUSSION}

The hypothesis that gammaglobulins play a role in the pathophysiology of rheumatoid arthritis and systemic lupus erythematosus is supported by a number of well documented observations. An increased gammaglobulin synthetic rate, as great as 5 times normal, has been noted in our laboratory (20) and elsewhere (23-25) in both rheumatoid arthritis and systemic lupus erythematosus. Auto-antibodies against multiple host cell and serum factors including HLA antigens, have been well characterized in these diseases (26-29). In addition, these abnormal antibodies in the form of circulating immune complexes have been shown to possess complement-fixing ability and the capacity to mediate tissue injury $(30,31)$.

The observations made of suppressed primary antibody responses (3) and inhibition of experimentally induced delayed hypersensitivity (2) by purine analogues may have little application to the treatment of diseases in which the proposed sensitization has already occurred and is well established. The suppression of established gammaglobulin synthesis in general by azathioprine would suggest that the synthesis of abnormal autoantibodies is also being suppressed, and in contrast to the effects on experimentally induced immunity, these changes may have important clinical significance. Our findings of the decline to normal or near normal levels of hyperactive gammaglobulin synthesis in these patients, associated with a reduction in antiglobulin antibody titers and a favorable clinical response after azathioprine therapy, suggests that either suppression of gammaglobulin synthesis is an important part of the therapeutic action of azathioprine or that this effect accompanies a decrease in disease activity caused by an unrelated mechanism of drug action. The experimental turnover data in azathioprine-treated rabbits (10) and evidence of in vitro inhibition of antibody synthesis by azathioprine (32) would suggest that azathioprine effects gammaglobulin synthesis directly.

Despite the demonstration in animals that purine analogues, when administered in large doses, can produce a depression in serum gammaglobulin, the usual smaller therapeutic dose in man has been presumed not to influence gammaglobulin synthesis because serum gammaglobulin concentrations generally remained unchanged $(7,11,12)$. In our studies, more than half of the patients showing a significant reduction in IgG synthesis did not demonstrate any significant change in IgG serum concentration. The presumed mechanism for an unchanging serum concentration is a slowing of catabolism in response to a decrease in synthetic rate and serum concentration. The homeostatic mechanism maintaining serum gammaglobulin levels in a steady state has been particularly well documented for IgG immunoglobulin in both animals $(33-35)$ and man $(36,37)$. A most striking experiment of nature demonstrating this phenomenon is the unusually slow catabolism or prolonged half-life of serum IgG in patients with hypogammaglobu- 
linemia secondary to decreased gammaglobulin synthesis. Therapeutic doses of azathioprine therefore may significantly reduce immunoglobulin synthesis without necessarily reducing serum IgG concentration.

The observation in our patients of essentially no change in the type or intensity of skin test delayed type hypersensitivity, although not precluding more subtle changes, may suggest that cellular immunity is less affected than humoral immunity. Sparing of cellular immunity may be related to the specificity described by Lemmel, Hurd, and Ziff (38) for 6MP and cyclophosphamide with regard to the type of leukocyte primarily affected by drug treatment. The observations of defective cellular as well as humoral immunity in patients treated with azathioprine for homograft rejection and chronic nephritis $(39,40)$, may be a consequence of the combined effects of multiple drugs and may not be true of treatment with azathioprine alone.

Inhibition by purine analogues of the mononuclear cell phase of experimental local inflammatory responses has been described $(41,42)$. Although this antiinflammatory effect may contribute to clinical benefit, the $6-8 \mathrm{wk}$ delay before clinical improvement is observed and the failure of drug treatment to block the delayed hypersensitivity inflammatory response to skin test antigens suggests that azathioprine is not acting primarily as an anti-inflammatory agent.

Our studies demonstrate that gammaglobulin synthesis is significantly reduced by azathioprine therapy. Continued investigation into the immunologic effects of drugs such as azathioprine may provide indirect clues to the pathophysiology of diseases such as rheumatoid arthritis and systemic lupus erythematosus and may further identify the specificities of immunosuppressive drug action with regard to their efficacy and toxicity.

\section{ACKNOWLEDGMENTS}

The technical assistance of M. Cragen, W. Victory, I. Ban, A. M. Flesher, and S. Lillefjeld is gratefully acknowledged.

This work was supported in part by a Veterans Administration Research and Education Associate award, U. S. Public Health Service Grants GM 15759 and RR-00238 and contract AT-04 Gen12 between the U. S. Atomic Energy Commission and the University of California, Los Angeles, Calif.

\section{REFERENCES}

1. Elion, G. B., and G. H. Hitchings. 1965. Metabolic basis for actions of purines and pyrimidines. In Advances in Chemotherapy. A. Golden, F. Hawking, and R. J. Schnitzer, editors. Academic Press Inc., New York. 2: 91.

2. Borel, Y., and R. Schwartz. 1964. Inhibition of immediate and delayed hypersensitivity in rabbit by 6 -mercaptopurine. J. Immunol. 92: 754.

3. Schwartz, R., J. Stark, and W. Dameshek. 1958. Ef- fect of 6-mercaptopurine on antibody production. Proc. Soc. Exp. Biol. Med. 99: 164.

4. LaPlante, E. S., R. Condie, and R. Good. 1962. Prevention of secondary immune response with 6-mercaptopurine. J. Lab. Clin. Med. 59: 542.

5. Levin, R. H., M. Landy, and E. Frei. 1964. Effect of 6-mercaptopurine on immune response in man. N. Engl. J. Med. 271: 16.

6. Maibach, H. I., and W. L. Epstein. 1965. Immunologic responses of healthy volunteers receiving azathioprine (Imuran). Int. Arch. Allergy Appl. Immunol. 27: 102 .

7. Swanson, M. A., and R. S. Schwartz. 1967. Immunosuppressive therapy: the relation between clinical responses and immunologic competence. N. Engl. J. Med. $277: 163$

8. Wolff, S. M., and H. C. Goodman. 1963. Effect of purine antimetabolites on serum globulins in the rabbit. Proc. Soc. Exp. Biol. Med. 112: 416.

9. Herrod, H. G., M. Myers, K. S. Self, and M. D. Cooper. 1970. Suppression of IgM and IgG synthesis in young rabbits by 6-methyl mercaptopurine treatment. J. Lab. Clin. Med. 76: 1 .

10. Mott, P. D., R. D. Wochner, and S. M. Wolff. 1968. The effect of 6-mercaptopurine on the turnover of $\mathrm{I}^{131}$ gammaglobulins and $\mathrm{I}^{125}$-albumin in rabbits. J. Pharmacol. Exp. Ther. 159: 211.

11. Brocteur, J., and C. Moens. 1965. Treatment of rheumatoid arthritis with immunosuppressive drugs. II. Immunological study. Acta Rheumatol. Scand. 11: 221.

12. Mistilus, S. P., and C. R. B. Blackburn. 1967. The treatment of active chronic hepatitis with 6-mercaptopurine and azathioprine. Australas. Ann. Med. 16: 305.

13. McFarlane, A. S. 1957. The behavior of I'1-labeled plasma proteins in vivo. Ann. N. Y. Acad. Sci. 70: 19.

14. Ropes, M. W., G. A. Bennett, S. Cobb, R. Jacox, and R. A. Jessar. 1959. 1958 revision of diagnostic criteria for rheumatoid arthritis. Arthritis Rheum. 2: 16.

15. Singer, J. M., and C. M. Plotz. 1956. The latex fixation test. I. Applications to the serological diagnosis of rheumatoid arthritis. Am. J. Med. 21: 888 .

16. Rose, H. M., C. Ragan, E. Pearce, and M. O. Lipman. 1958. Differential agglutination of normal and sensitized sheep erythrocytes by sera of patients with rheumatoid arthritis. Proc. Soc. Exp. Biol. Med. 68: 1.

17. Mancini, G., J. P. Vaerman, A. O. Carbonara, and J. F. Heremans. 1963. A single radial diffusion method for the immunological quantitation of proteins. Protides Biol. Fluids, Proc. XI Colloq. 370.

18. Barnett, E. V., J. J. Condemi, J. P. Leddy, and J. H. Vaughan. 1964. Gamma-2, gamma-1A and gamma-1M antinuclear factors in human sera. J. Clin. Invest. 43: 1104.

19. McFarlane, A. S. 1958. Efficient trace labelling of protein with iodine. Nature (Lond.). 182: 53.

20. Levy, J., E. V. Barnett, N. S. MacDonald, and J. R. Klinenberg. 1970. Altered immunoglobulin metabolism in systemic lupus erythematosus and rheumatoid arthritis. J. Clin. Invest. $49: 708$.

21. Berson, S. A., R. S. Yalow, S. S. Schreiber, and J. Post. 1953. Tracer experiments with $\mathrm{I}^{191}$ labeled serum albumin: distribution and degradation studies. J. Clin. Invest. $32: 746$.

22. Sterling, K. 1951. The turnover rate of serum albumin in man as measured by $\mathrm{I}^{181}$-tagged albumin. $J$. Clin. Invest. 30: 1228. 
23. Olhagen, B., G. Birke, L. O. Plantin, and S. Ahlinder. 1963. Isotope studies of gammaglobulin catabolism in collagen disorders. Acta Rheumatol. Scand. 9: 88.

24. Anderson, S. B., and K. B. Jensen. 1965. Metabolism of G-globulin in collagen disease. Clin. Sci. (Oxf.). 29: 533 .

25. Wochner, R. D. 1970. Hypercatabolism of normal IgG; an unexplained immunoglobulin abnormality in the connective tissue diseases. J. Clin. Invest. 49: 454.

26. Kunkel, H. G., and E. M. Tan. 1964. Autoantibodies and disease. Adv. Immunol. $4: 351$.

27. Barnett, E. V., R. F. Bakemeier, J. P. Leddy, and J. H. Vaughan. 1965. Heterogeneity of antinuclear factors in lupus erythematosus and rheumatoid arthritis. Proc. Soc. Exp. Biol. Med. 118: 803.

28. Mellors, R. C., A. Nowoslawski, L. Korngold, and B. L. Sengson. 1961. Rheumatoid factor and pathogenesis of rheumatoid arthritis. J. Exp. Med. 113: 475.

29. Terasaki, P. I., V. D. Mottironi, and E. V. Barnett. 1970. Cytotoxins in disease; autocytotoxins in lupus. N. Engl. J. Med. 283 : 724.

30. Zvaifler, N. J., and P. Schur. 1968. Reactions of aggregated mercaptoethanol treated gammaglobulin with rheumatoid factor-precipitin and complement fixation studies. Arthritis Rheum. 11: 523.

31. Tesar, J. T., and F. R. Schmid. 1970. Conversion of soluble immune complexes into complement fixing aggregates by IgM rheumatoid factor. J. Immunol. 105: 1206.

32. Bach, J. F., M. Dardanne, and C. Fournier. 1969. In vitro evaluation of immunosuppressive drugs. Nature (Lond.). 222: 998.

33. Fahey, J. L., and A. G. Robinson. 1963. Factors con- trolling serum $\gamma$-globulin concentration. J. Exp. Med. $118: 845$.

34. Sell, S., and J. L. Fahey. 1964. Relationship between $\boldsymbol{\gamma}$-globulin metabolism and lower serum $\boldsymbol{\gamma}$-globulin in germ free mice. J. Immunol. 93: 81.

35. Sell, S. 1964. Evidence for species differences in the effect of serum globulin concentration on $\boldsymbol{\gamma}$-globulin catabolism. J. Exp. Med. 120: 967.

36. Waldmann, T. A., and P. J. Schwab. 1965. IgG (7S gamma globulin) metabolism in hypogammaglobulinemia: studies in patients with defective gammaglobulin synthesis, gastrointestinal protein loss or both. J. Clin. Invest. $44: 1523$.

37. Soloman, A., T. A. Waldmann, and J. L. Fahey. 1963. Metabolism of normal $6.6 \gamma$-globulin in normal subjects and in patients with macroglobulinemia and multiple myeloma. J. Lab. Clin. Med. 62: 1 .

38. Lemmel, E., E. R. Hurd, and M. Ziff. 1969. Differential effects of 6-MP and cyclophosphamide on immunologic features in NZB mice. Arthritis Rheum. 12: 674.

39. Kirkpatrick, C. H., W. E. C. Wilson, and D. W. Talmage. 1964. Immunologic studies in human organ transplantation. J. Exp. Med. 119: 727.

40. Rubin, A. L., K. H. Stenzel, K. Hirschhorn, and F. Bach. 1964. Histocompatibility and immunologic competence in renal homotransplantation. Science (Wash., (D. C.). $143: 815$.

41. Page, R., R. M. Condie, and R. A. Good. 1962. Effect of 6-mercaptopurine on inflammation. Am. J. Pathol. 40: 519 .

42. Hurd, E. R., and M. Ziff. 1968. Studies on the antiinflammatory action of 6-mercaptopurine. J. Exp. Med. 128: 785 . 